\title{
Multimedia in improving informed consent for caesarean section: A randomised controlled trial
}

\author{
Running Title \\ Multimedia in consent for caesarean section
}

Authors

TRUONG Alice ${ }^{1}$, ELLETT Lenore ${ }^{1}$, HICKS Lauren ${ }^{1}$, PELL Gabrielle ${ }^{1}$, WALKER Susan P 1,2

${ }^{1}$ Mercy Perinatal, Mercy Hospital for Women, Melbourne, Victoria, Australia

${ }^{2}$ Department of Obstetrics and Gynaecology, University of Melbourne, Melbourne, Victoria, Australia

\section{Corresponding Author:}

Dr Alice Truong

RANZCOG Advanced Trainee

Mercy Perinatal

Mercy Hospital for Women

163 Studley Rd, Heidelberg VIC 3084, Australia

Phone: +61384584444

Email: alice.truong@trainee.ranzcog.edu.au

\section{Other author details:}

Dr Lenore Ellett, Obstetrician \& Gynaecologist

Email: 1ellett@mercy.com.au

Dr Lauren Hicks, RANZCOG Advanced Trainee

Email: lauren.hicks@mac.com

This is the author manuscript accepted for publication and has undergone full peer review but has not been through the copyediting, typesetting, pagination and proofreading process, which may lead to differences between this version and the Version of Record. Please cite this article as doi: $10.1111 / \mathrm{AJ} 0.13124$

This article is protected by copyright. All rights reserved 
Ms Gabrielle Pell, Research Midwife

Email: Gfleming@mercy.com.au

Professor Sue Walker, Director Perinatal Medicine

Email: spwalker@unimelb.edu.au

The authors declare that they have no conflict of interest.

\section{Acknowledgements}

We thank the Norman Beischer Medical Research Foundation for their financial support of this project, and thank Dr Andrew Beischer and Ms. Cathryn Curtin for their contribution in development of this multimedia module. The trial was registered with the Australian New Zealand Clinical Trials Registry (ACTRN12616000430437).

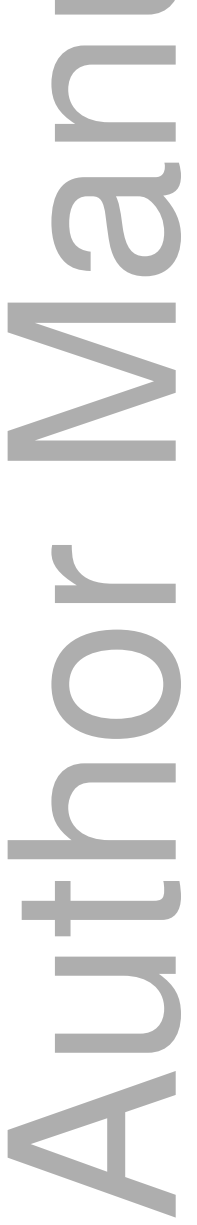




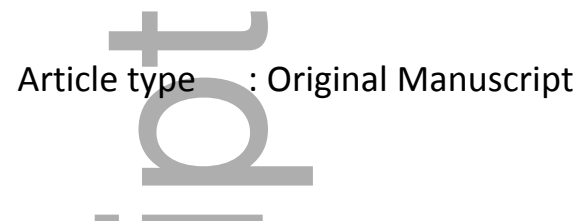

\section{Multimedia in improving informed consent for \\ caesarean section: A randomised controlled trial}

\section{Running Title}

Multimedia in consent for caesarean section

Word count:

Main text $-2,499$

Abstract -250

Tables - 2

Figures - 2

Appendices - 2

\section{Keywords (5):}

Caesarean section, informed consent, multimedia, knowledge, anxiety

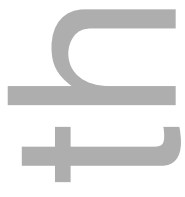

\section{ABSTRACT}

Background: Multimedia modules have been used as an adjunct to improve patient knowledge and recall for various elective surgical procedures, but have been incompletely evaluated in patients undergoing caesarean section. 
Aims: To compare the use of a supplementary multimedia module with written information in improving the informed consent process prior to elective caesarean section.

Materials and methods: This was a prospective randomised controlled trial (ACTRN12616000430437). Primary outcomes were knowledge and anxiety scores immediately following the intervention and on the day of surgery. Secondary outcomes were patient satisfaction, length of stay, time to cessation of analgesia, and patient assessment of the consent types.

Results: 75 patients completed the study. Both multimedia module and written information groups demonstrated a significant increase in knowledge scores with no difference between the groups. In the multimedia-assisted consent group, scores improved from baseline by $+2.31(\mathrm{p}<0.001)$ immediately after watching the multimedia module and by $+2.41(\mathrm{p}<0.001)$ on the day of surgery. In the written information group, scores improved by $+1.76(<0.001)$, and $+2.31(\mathrm{p}<0.001)$ respectively. There was no adverse impact on anxiety in either group. Patient-reported understanding (92.4\% vs $78.5 \%, \mathrm{p}=0.001)$, and helpfulness $(90.1 \%$ vs $73.3 \%$, $\mathrm{p}=0.001$ ) was significantly higher in the multimedia module group than in the written information group. The multimedia module was assessed as 'slightly too long' and provided 'slightly too much information'.

Conclusions: Multimedia modules are a valuable adjunct to traditional processes of obtaining informed consent for elective caesarean section, and should be offered and made available to patients prior to surgery.

\section{Introduction}

Informed consent is the "voluntary authorisation by a patient... with full comprehension of the risks involved"1 to a medical or surgical treatment. Current evidence suggests that neither patients nor doctors are optimally prepared for the informed consent process for common surgical procedures ${ }^{2-4}$. Factors that can impair the information exchange between doctors and patients include language 
differences, use of medical jargon, and poor baseline health literacy ${ }^{5}$. While it is important that patients and doctors engage in an individualised dialogue about patientspecific risks and benefits, an adjunct to the informed consent process may provide patients with consistent, standardised information in a manner that they can easily understand and retain.

The most commonly used patient education tool is written material. However, there is limited evidence that written materials improve comprehension ${ }^{6,7}$, with some studies demonstrating they can increase confusion ${ }^{8}$. Visual aids that graphically present numerical expressions of probability have been shown to be beneficial for people who have low numeracy and risk literacy ${ }^{9}$. Multimedia presentations, which present auditory and visual information concurrently, have been demonstrated to increase knowledge recall without impacting on patient anxiety ${ }^{2,10-11}$. Trials assessing audiovisual aids and multimedia presentations for the purposes of improving informed consent for various surgical procedures including knee arthroscopy, laparoscopic cholecystectomy, colonoscopy and laparoscopy for tubal ligation or pelvic pain ${ }^{11-16}$ have all demonstrated improved knowledge levels and high patient acceptability

Caesarean section is now the most commonly performed surgical procedure in the world $^{12}$. In keeping with global trends, caesarean section rates in Australia and New Zealand have steadily increased from $19 \%$ in $1990^{17}$ to $34 \%$ in $2016^{18}$. Audits of consent for caesarean section have demonstrated deficiencies in the documentation of rare but significant risks such as hysterectomy, implications for the fetus such as respiratory morbidity and laceration or trauma, implications for future pregnancies ${ }^{19.20}$, post-operative pain and the associated difficulties with caring for a newborn baby ${ }^{21,22}$.

A reliable process of obtaining consent for this commonly performed procedure is necessary to assist patients in making an informed decision. Multimedia modules that use standardised language, provide audiovisual cues and probability aids better cater 
for variations in health literacy among patient groups, and so may be expected to improve the consent process.

\section{Objectives}

The aim of this study was to assess whether the viewing of a multimedia module $(\mathrm{MM})$ improves the informed consent process for elective caesarean section. Specifically, we sought to determine whether MM-assisted consent increases patient knowledge and satisfaction regarding caesarean section without increasing anxiety levels when compared with standard care: written information (WI)-assisted consent.

\section{Materials and Methods}

A prospective randomised-controlled trial comparing the use of Multimedia Module (MM)-assisted consent and Written Information (WI)-assisted consent prior to term elective caesarean section was performed.

Study participants were recruited at a tertiary obstetric hospital in Melbourne, Australia. Women who were scheduled for an elective caesarean section were identified and approached at their antenatal clinic appointment two to four weeks prior to their procedure date. Eligible patients were women undergoing their first or second caesarean section for any reason, who had been reviewed by a doctor and signed a surgical consent form. Non-English-speaking women were excluded.

Following enrolment, participants were asked to complete a baseline knowledge test regarding caesarean section and a baseline anxiety score. They were then randomly allocated by a computer-generated sequence using a 1:1 ratio to viewing a MM or reading a written pamphlet. Using opaque envelopes, assignment was concealed from primary investigators and participants up until consent for the study was obtained.

The content of the MM was developed by an expert panel comprising a practising maternal fetal medicine specialist (SPW), midwife and anaesthetist. The MM was 
pilot-tested prior to commencement of the trial. The 26-minute MM presentation included information on common indications for caesarean section, a description of the surgical procedure and anaesthetic techniques, the expected recovery process in hospital and at home. A visual probability aid was employed to depict common procedural risks such as risk of blood transfusion, venous thromboembolism and visceral injury (Figure 2). The MM was viewed on an iPad at the patients' antenatal clinie appointment and a weblink was provided to patients to allow them unlimited access to the MM from home. The MM can be freely accessed at https://www.ranzcog.edu.au/Womens-Health/Patient-Information-Guides/Preparingfor-Surgery/Caesarean-Section-Video

Women randomised to WI-assisted consent received the written information pamphlet on caesarean section published in 2006 by the Royal Australian and New Zealand College of Obstetricians and Gynaecologists (RANZCOG). This pamphlet is commonly provided to patients at the time of obtaining consent for caesarean section at this institution. The pamphlet and the MM contained similar information, but differed in their wording and presentation.

\section{Knowledge and Anxiety Assessment}

An 11-question knowledge test based on the information contained in the written pamphlet and the MM was designed by the authors and several specialist obstetricians (Appendix 1). Possible scores ranged from 0-11, with patients who answered incorrectly or chose "Not sure" receiving no score for that item. Anxiety levels were assessed with a 6-item version of the Spielberger 20-item State-Trait Anxiety Inventory (STAI) (Appendix 2). This simplified, short form has been validated against the standard inventory ${ }^{23}$. Possible scores ranged from 3 to 12 in each category of State or Trait anxiety, or 6 to 24 for a combined score, with higher scores indicating higher levels of anxiety.

The knowledge test and anxiety scores were repeated immediately after reading the written pamphlet or watching the MM, and again on the day of surgery. Women were asked to assess the usefulness, and appropriateness of verbal consent and their 
randomised intervention on a $10-\mathrm{cm}$ visual analogue scale (VAS). They were asked if in the future, they would prefer verbal consent alone, or if they wished to be supplemented with written information, a MM or both.

Six weeks after their delivery, women were followed up with a phone call to identify any postoperative complications, to assess their recovery, analgesia usage, and to rate their satisfaction with their caesarean section and the informed consent process using a score out of 10 .

The primary outcomes were change in knowledge and anxiety scores immediately after the intervention, and on the day of surgery. The secondary outcomes were patient satisfaction with the procedure and the consent process, length of stay, time to cessation of analgesia, and patient assessment of the usefulness and helpfulness of the consent process types.

This early phase trial was powered for a $15 \%$ difference in knowledge score between groups, with an anticipated mean baseline knowledge score of $60 \%$. The required sample size was 27 per group. This was calculated using the two-sample t-test, based on a power test of 0.8 . We allowed for a $30 \%$ loss to follow up rate and aimed to recruit a total of 80 patients into the study. Data was analysed using the software package Stata (StataCorp. Version 12.1, 2011). Continuous variables were assessed for normality and compared using a Student's t-test.

Ethical approval for the study was obtained from the Human Research and Ethics Committee of the Mercy Hospital for Women (R13-43). All women provided written consent for their participation in the study. The trial was registered with the Australian New Zealand Clinical Trials Registry (ACTRN12616000430437).

\section{Results}

Study participants were recruited between April 2014 and August 2015. Of 253 eligible patients, 130 were approached to participate and 80 were consented to randomisation. The primary reason for declining to participate was lack of time. 
Patients were randomised equally to each intervention. 38 patients in the WI-assisted consent group, and 37 patients in the MM-assisted consent group completed the consent process and post-education knowledge and anxiety scores. 9 and 7 patients from each respective group were unable to complete the day of surgery assessment due to delivery prior to the planned caesarean section date. Complete data was obtained for analysis for 29 patients in the WI-group and 30 patients in the MM group (Figure 1).

Patients of both groups were similar with respect to age, gestation, parity and level of education (Table 1). A higher proportion of patients had attended antenatal classes in the WI consent group (65.8\%) compared with the MM consent group (40.5\%).

Baseline knowledge and anxiety scores were similar between the two groups.

There was a significant improvement in knowledge scores from baseline in both groups immediately after the intervention $(\mathrm{WI}+1.76, \mathrm{p}<0.0001 ; \mathrm{MM}+2.31$, $\mathrm{p}<0.001$ ), and this was maintained on the day of surgery two to four weeks later (WI $+2.21, \mathrm{p}<0.0001 ; \mathrm{MM}+2.41, \mathrm{p}<0.0001)$ (Table 2). While there was a trend to greater knowledge improvement in the MM group, there was no statistically significant differences in change in knowledge between the two groups, either immediately postintervention or on the day of surgery. Anxiety scores were similar between the groups before and after receiving the intervention, with slightly decreased anxiety immediately after the intervention (WI $-0.47, \mathrm{p}=0.08 ; \mathrm{MM}-0.54, \mathrm{p}=0.08$ ), and slightly increased on the day of surgery (WI $+0.86, p=0.18$; $M M+1.69, p=0.02$ ). This was also not statistically significant between the two groups.

The MM was rated significantly higher than the pamphlet for ease of understanding on a $10 \mathrm{~cm}$ visual analogue score (WI 78.5; MM 92.4, p=0.001) and helpfulness (WI 73.3; MM 90.1, $\mathrm{p}=0.0001$ ). Postnatal follow-up showed that preparedness was higher in the MM group (WI 8.1; MM 8.7, p=0.16), however this finding was not statistically significant. There were similar rates of satisfaction (WI 8.4; MM 8.5, $\mathrm{p}=0.85$ ) amongst the two groups. Participants rated the WI-assisted consent as providing 'just the right amount' of information (VAS score 53.9) and the MM- 
assisted consent process as providing 'slightly too much' information (VAS score 67.6, $\mathrm{p}=0.014)$. The MM consent process was considered 'slightly too long' in duration (VAS score 60.6).

Almost all participants stated that in future pregnancies, they would want to be provided with supplemental information in any format rather than undergoing verbal consent alone. $65 \%$ of patients preferred having access to both the pamphlet and MM, $20 \%$ preferred the pamphlet, and $10 \%$ preferred the MM. The majority of patients $(86.7 \%)$ who watched the MM stated that the best time for viewing would be at home.

The most common complications reported by patients included prolonged bleeding post-operatively, wound infection, failure of spinal anaesthetic and post-dural puncture headache. Length of stay in hospital was similar between the two groups (WI 4.8 days vs MM 4.9 days, $\mathrm{p}=0.85$ ). Time to cessation of analgesia was 12.7 days for the WI consent group and 10.6 days for the MM consent group ( $\mathrm{p}=0.36$ ).

\section{Discussion}

Our study demonstrated that MM-assisted consent improved patient knowledge about caesarean section from baseline, both immediately after viewing the module and on the day of surgery 2-4 weeks later. This finding is consistent with similar studies that have demonstrated an overall improvement in comprehension with the use of $\mathrm{MM}^{10,11,13-16}$, albeit with variable levels of recall of knowledge over time. One study in the United States showed that patients being consented for caesarean section with multimedia on the day of surgery recalled more risks and benefits on day 1 postdelivery than those who had only been consented verbally ${ }^{24}$, however this difference was no longer significant at 6 weeks post-delivery. In another study examining informed consent for knee arthroscopy ${ }^{15}$, patients consented with a MM had higher knowledge scores than patients who had verbal or pamphlet consent, up to 6 weeks after surgery.

We included the written pamphlet in our control group as we felt this was a part of standard care, and found no difference in the change in knowledge between the 
groups in either direction. Similar studies examining the use of MMs did not administer written information to the control group ${ }^{11,24}$, thus failing to make the important comparison with 'optimal' standard care.

The literature is conflicting in regard to MMs and their effect on pre-operative anxiety levels. In a recent systematic review, 12 trials assessed anxiety levels - 7 reported a decrease in anxiety, 3 showed increased anxiety and the remaining showed no difference ${ }^{10}$. Our study showed no statistically significant difference between the two groups in terms of anxiety levels post-education or on the day of surgery. This negative finding suggests that the provision of information in an audiovisual format compared with a written format does not have a significant harmful impact on the patient's mental state.

The MM was rated higher than the written pamphlet for ease of understanding and helpfulness for caesarean section, however it would have benefited from containing slightly less information and being slightly shorter in duration. This study demonstrates that women value additional information prior to their caesarean section, with $67.3 \%$ of women expressing that they would like to have access to both the written pamphlet and the MM in the future. In reality, many first caesarean sections are done in an emergency setting and it is unlikely that the use of a MM would be feasible in this setting. A solution would be to provide access to this readilyavailable $\mathrm{MM}$ as a part of antenatal education for all women. The MM has the advantage of being viewed in clinic, during antenatal classes or at home, depending on personal preference. With $89 \%$ of Australians now owning a smartphone ${ }^{25}$, and mobile applications being increasingly utilised for health information ${ }^{26}$, it is important that reliable education tools incorporating multimedia are developed for and are easily accessible on mobile devices.

The limitations of our study are acknowledged. While our measures of anxiety were assessed with validated instruments, our study used a knowledge questionnaire that had not been previously validated as an assessment tool. On review of the literature, there are no published validated questionnaires pertaining to specific issues 
surrounding caesarean section; this is not an isolated issue for caesarean section. In a systematic review of 33 similar studies examining the use of MM in informed consent for other elective surgical procedures, 22 studies used internally produced nonvalidated questionnaires $^{12}$.

Prior to the study interventions, $64.3 \%$ of participants had accessed other information including the written pamphlet, the internet, books or spoken to other women who had undergone a caesarean section. Approximately $85 \%$ of study participants had undergone a previous caesarean section, many of them in an emergency setting, and their personal experience with the procedure may have impacted on their perception of caesarean section and its risks and benefits. Despite this, there was a statistically significant improvement in knowledge scores in both groups. This would suggest that the adjunctive materials are beneficial even for women who have prior knowledge or experience with caesarean section.

Patients who are provided with MMs as an adjunct to the informed consent process for caesarean section demonstrate an improvement in knowledge without increased anxiety immediately after watching the MM and on the day of surgery. MMs were not significantly different in knowledge improvement when compared to WI as an adjunct to the informed consent process for caesarean section, but were rated higher for understanding and helpfulness.

While the doctor patient dialogue is a crucial part of the informed consent process, our study demonstrates that patients value supplementary information in both written and multimedia formats. In addition to the current standard of informed consent, this easily accessible multimedia module should be offered and made available to patients prior to planned caesarean section.

\section{References}

1. Leclercq WKG, Keulers BJ, Scheltinga MRM, et al. A Review of Surgical Informed Consent: Past, Present and Future. A Quest to Help Patients Make Better Decisions. World J Surg 2010; 34: 1406-1415. 
2. Farrell, EH, Whistance RN, Phillips K, et al. Systematic review and metaanalysis of audio-visual information aids for informed consent for invasive healthcare procedures in clinical practice. Patient Educ Couns 2014; 94: 2032.

3. $\quad$ Stanitski CL. "Informed" ??? Consent. J Pediatr Orthop 2006. 26(3).

4. Landro, L. Consent forms that patients can understand. Wall St J 2008;

- February 6: D1, D3.

5. Wanzer MB, Wojtaszcyzk AM, Schimert J, Missert, et al. Enhancing the "Informed" in Informed Consent: A Pilot Test of a Multimedia Presentation. J Health Commun 2010. 25: 365-374.

6. Richardson, V. Patient comprehension of informed consent. J Periop Prac 2013. 23(1\&2): 26-30.

7. Rieger N, Kennedy R, Farrell S, et al. Informed consent, patient satisfaction and length of hospitalisation: the contribution of written information leaflets. Health Promot J Austr 1999. 9(3): 188-191.

8. Kusec S,Oreskovic S, Skegra M, et al. Improving comprehension of informed consent. Patient Educ Couns 2006. 60: 294-300.

9. Garcia-Retamero R, Cokely ET. Communication Health Risks With Visual Aids. Curr Dir Psychol Sci 2013. 22(5): 392-399.

10. Nehme J, El-Khani U, Chow A, et al. The Use of Multimedia Consent Programs for Surgical Procedures: A Systematic Review. Surg Innov 2013; 20(1): 13-23.

11. Ellett L, Villegas R, Beischer A, et al. Use of a Multimedia Module to Aid the Informed Consent Process in Patients Undergoing Gynecologic Laparoscopy for Pelvic Pain: Randomized Controlled Trial. J Minim Invasive Gynecol 2014; 21: 602-611.

12. Souza JP, Betran AP, Dumont A, et al. A global reference for caesarean section rates (C-Model): a multicountry cross-sectional study. Br J Obstet Gynaecol 2015. 123(3).

13. Beamond BM, Beischer AD, Brodsky, Leslie H. Improvement in Surgical Consent with a Preoperative Multimedia Patient Education Tool: A Pilot Study. Foot Ankle Int 2009. 30(7). 
14. Batuyong E, Birks C, Beishcer AD. The Use of Multimedia as an Adjunct to the Informed Consent Process for Ankle Ligament Reconstruction Surgery. Foot Ankle Spec 2012. 5(3).

15. Cornoiu A, Beischer AD, Donnan L, et al. Multimedia patient education to assist the informed consent process for knee arthroscopy. Aust N J Z Surg 2011. 81: 176-180.

16. Thanapongsathorn W, Inchit C, Phunya J. Audiovisual Multimedia Combined with Standard, Verbal, Informed Consent; Enhancing the Satisfaction and Comprehension of Surgical Patients: A Comparative Trial in Patients Undergoing Laparoscopic Cholecystectomies at the HRH Princess Maha Chakri Sirindhorn Medical Center, Thailand. Surg Sci 2012. 3: 393-398.

17. Betran AP, Ye J, Moller AB, et al. The Increasing Trend in Caesarean Section Rates: Global, Regional and National Estimates: 1990-2014. PLoS ONE 2016; 11(2): p. eo148343.

18. Australian Institute of Health and Welfare 2018. Australia's mothers and babies 2016 - in brief. Perinatal statistics series no. 34. Cat no. PER 97. Canberra: AIHW.

19. Raut A, Raut N, Rhodes C. The validity of consent for caesarean section. Int J Gynaecol Obstet 2009. 107S2: S413-S729.

20. Glennon K, Tower C, Gillham J, et al. An audit of informed consent for cesarean section and instrumental delivery in a tertiary referral center in the United Kingdom. Clinical Audit 2011. 3: 1-5.

21. Kolip P, Buchter R. Involvement of first-time mothers with different levels of education in the decision-making for their delivery by a planned Caesarean section. Women's satisfaction with information given by gynaecologists and midwives. J Public Health 2009. 17(4): 273-280.

22. Robertson CG, Vergo CJ. The Quality of Consent - What is the Evidence? Aust NZ J Obstet Gynaecol 2013; 53(502-504).

23. Marteau TM, Bekker H. The development of a six-item short-form of the state scale of the Spielberger State-Anxiety Inventory (STAI). Br J Clin Psychol 1992. 31: 301-306. 
24. Ferzli M, Stifani B, Xie X, et al. Using a multimedia module to enhance patients' recall of cesarean birth informed consent: a randomized control trial. Am J Obstet Gynecol 2018. 218 (1): S44-S44.

25. Deloitte Mobile Consumer Survey 2018 - The Australian cut. Accessed at https://www2.deloitte.com/au/mobile-consumer-survey on 30 $30^{\text {th }}$ June 2019.

26. Medeiros KS, Silva BO, Queiroz JF et al. Assessment of mobile phone applications for care management in gynecology and obstetrics. Int J Gynecol Obstet 2019; 1-2.
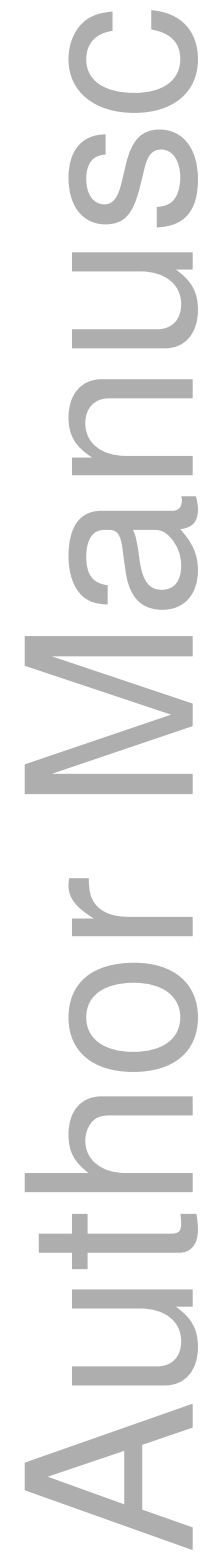


\section{List of figures}

Figure 1 - CONSORT Flow Diagram of Study

Figure 2-Representative Screenshots of Multimedia Module

\section{List of tables}

Table 1 - Baseline Demographic Data

Table 2 - Knowledge and Anxiety Scores

\section{List of appendices}

Appendix 1 - Knowledge Questionnaire

Appendix 2 -Anxiety Inventory

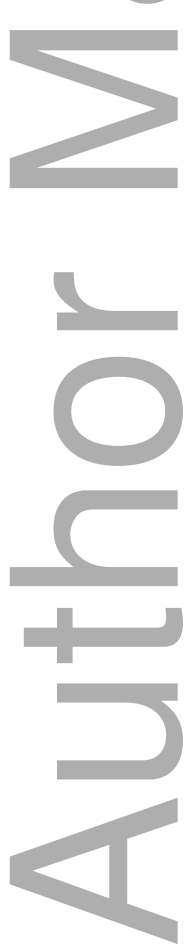

This article is protected by copyright. All rights reserved 
TABLE 1 - Baseline demographic data

\begin{tabular}{|c|c|c|}
\hline Variable & $\begin{array}{l}\text { Written information } \\
(\mathbf{n}=\mathbf{3 8})\end{array}$ & $\begin{array}{l}\text { Multimedia } \\
\text { module }(n=37)\end{array}$ \\
\hline Patient age, mean (SD) & $33.9(4.9)$ & $34.9(4.7)$ \\
\hline $\begin{array}{l}\text { Gestation at time of } \\
\text { LUSCS in weeks }\end{array}$ & $38.8(0.6)$ & $38.8(0.6)$ \\
\hline \multicolumn{3}{|l|}{ Parity - n (\%) } \\
\hline $\mathbf{0}$ & $2(5.3)$ & $2(5.4)$ \\
\hline 1 & $32(84.2)$ & $31(83.8)$ \\
\hline 2 & $4(10.5)$ & $4(10.8)$ \\
\hline Previous LUSCS - n (\%) & $32(84.2)$ & $32(86.5)$ \\
\hline \multicolumn{3}{|l|}{ Education level -n (\%) } \\
\hline Up to year 10 & $2(5.3)$ & $2(5.4)$ \\
\hline Up to year 12 & $11(28.9)$ & $5(13.5)$ \\
\hline TAFE & $4(10.5)$ & $7(18.9)$ \\
\hline University & $21(55.3)$ & $23(62.2)$ \\
\hline $\begin{array}{l}\text { Antenatal class attendance } \\
-\mathbf{n}(\%)\end{array}$ & $25(65.8)$ & $20(40.5)$ \\
\hline $\begin{array}{l}\text { Prior use of other } \\
\text { resources }-n(\%)\end{array}$ & $27(71.1)$ & $29(78.4)$ \\
\hline Pamphlet & $14(36.8)$ & $16(43.2)$ \\
\hline Internet & $11(28.9)$ & $10(27)$ \\
\hline Other (books, etc.) & $2(5.3)$ & $3(8.1)$ \\
\hline \multicolumn{3}{|l|}{ Baseline } \\
\hline Knowledge - mean (SD) & $6.82(2.0)$ & $6.36(2.1)$ \\
\hline \multicolumn{3}{|l|}{ Anxiety - mean (SD) } \\
\hline Total & $10.7(3.6)$ & $10.1(2.9)$ \\
\hline State & $5.0(1.8)$ & $4.7(1.4)$ \\
\hline Trait & $5.7(2.0)$ & $5.3(1.7)$ \\
\hline
\end{tabular}


TABLE 2 - Knowledge and Anxiety

\begin{tabular}{|c|c|c|c|c|c|c|c|c|c|c|c|c|}
\hline & \multicolumn{4}{|c|}{$\begin{array}{l}\text { Post-education } \\
\text { compared with baseline }\end{array}$} & \multicolumn{4}{|c|}{$\begin{array}{l}\text { Day of surgery } \\
\text { compared with baseline }\end{array}$} & \multicolumn{4}{|c|}{$\begin{array}{l}\text { Day of surgery } \\
\text { compared with post-education }\end{array}$} \\
\hline & WI & p-value & MM & p-value & WI & p-value & MM & p-value & WI & $\begin{array}{l}\text { p- } \\
\text { value }\end{array}$ & MM & $\begin{array}{l}\text { p- } \\
\text { value }\end{array}$ \\
\hline Knowledge & +1.76 & $<0.0001$ & +2.31 & $<0.0001$ & +2.21 & $<0.0001$ & +2.41 & $<0.0001$ & +0.28 & 0.24 & -0.21 & 0.47 \\
\hline \multicolumn{13}{|l|}{ Anxiety } \\
\hline Total & -0.47 & 0.08 & -0.54 & 0.08 & +0.86 & 0.18 & +1.69 & 0.02 & +1.3 & 0.06 & +2.0 & 0.003 \\
\hline State & -0.2 & & -0.1 & & +0.2 & & +1.0 & & +0.4 & & +0.9 & \\
\hline Trait & -0.3 & & -0.5 & & +0.7 & & +0.7 & & +0.9 & & +1.1 & \\
\hline
\end{tabular}




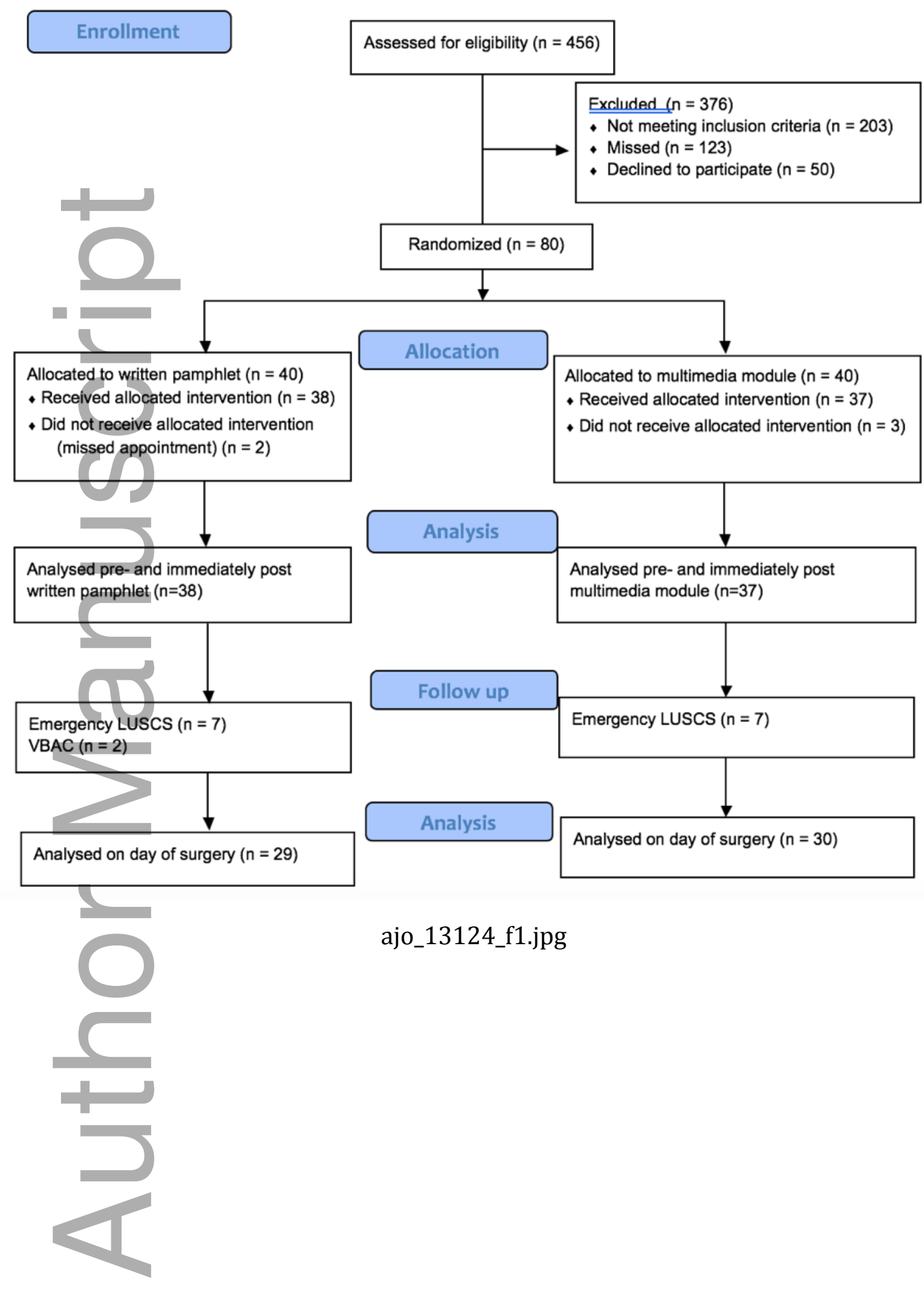

This article is protected by copyright. All rights reserved 


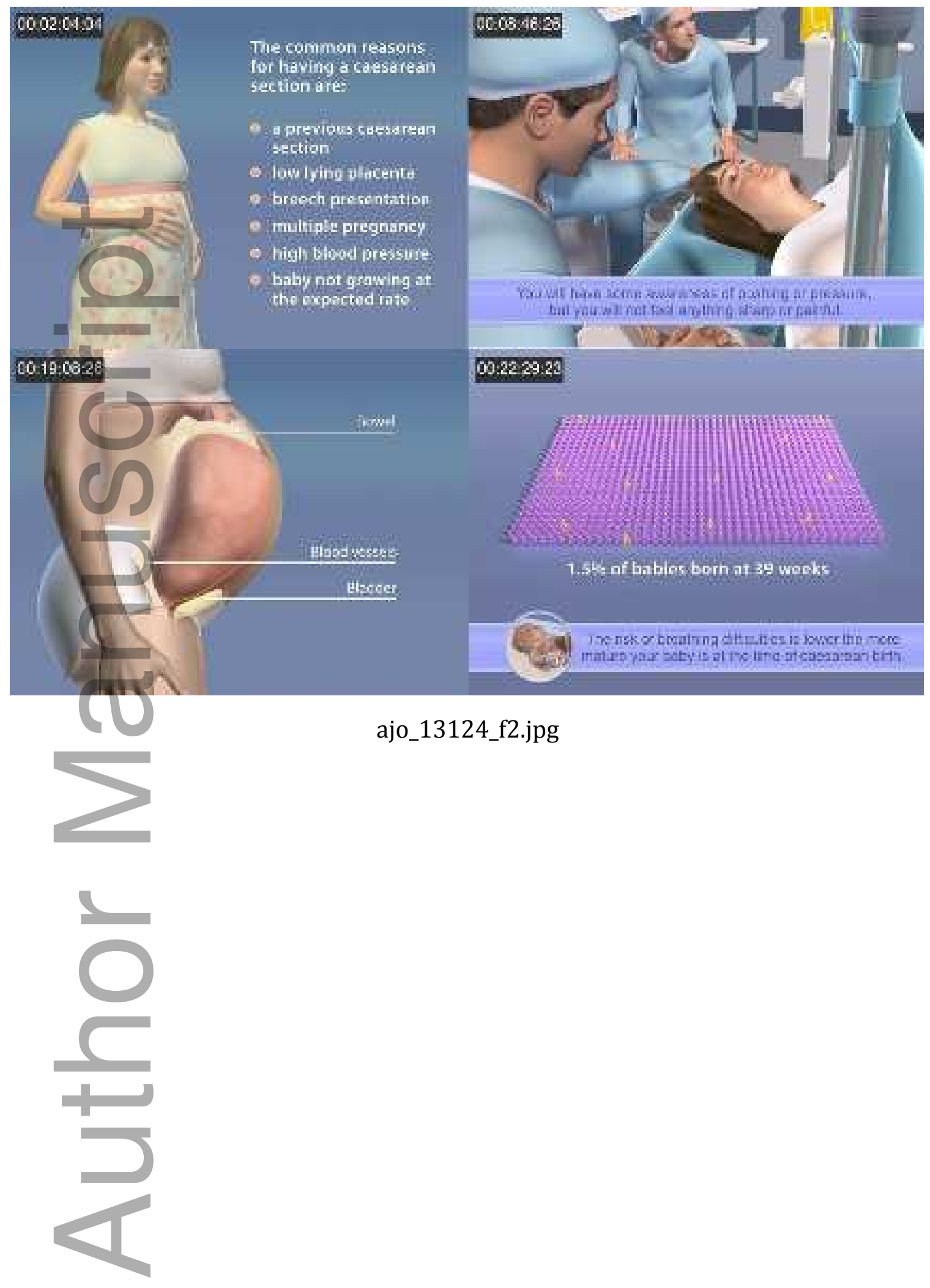




\section{University Library}

\section{- M M N E R VA A gateway to Melbourne's research publications}

Minerva Access is the Institutional Repository of The University of Melbourne

Author/s:

Truong, A;Ellett, L;Hicks, L;Pell, G;Walker, SP

Title:

Multimedia in improving informed consent for caesarean section: A randomised controlled trial

Date:

2020-01-28

\section{Citation:}

Truong, A., Ellett, L., Hicks, L., Pell, G. \& Walker, S. P. (2020). Multimedia in improving informed consent for caesarean section: A randomised controlled trial. AUSTRALIAN \& NEW ZEALAND JOURNAL OF OBSTETRICS \& GYNAECOLOGY, 60 (5), pp.683-689. https:// doi.org/10.1111/ajo.13124.

Persistent Link:

http://hdl.handle.net/11343/275328 